\title{
High temperature affects olive fruit fly populations in California's Central Valley
}

\author{
by Marshall W. Johnson, Xin-Geng Wang, \\ Hannah Nadel, Susan B. Opp, Kris Lynn- \\ Patterson, Judy Stewart-Leslie and Kent M. \\ Daane
}

Olive fruit fly commonly infests olives in California's Central Valley. Field studies indicate that trap counts for olive fruit fly adults in pesticide-free sites decrease in mid- and late summer and then rebound from September to November. Part of this decline is associated with heat stress that the flies experience in mid-July and August. Studies have shown that adult flies will die within a few days if they cannot access adequate amounts of water and carbohydrates. Flight ability is dramatically reduced when resources are unavailable. Olive fruit fly adults may use black scale honeydew as a carbohydrate source to help them survive hot periods. Heat also affects the fly's reproduction and immature stages within olive fruit. Geographic information system (GIS) maps may be useful for predicting the risk of olive fruit fly infestation.

$\mathrm{T}$ he discovery in 1998 and subsequent spread of the olive fruit fly throughout the major olive-producing areas of California dramatically affected the pest management activities practiced by growers. Prior to its introduction, the major arthropod pests targeted for control in California olives were olive scale (Parlatoria oleae Colvée) (Hempitera: Diaspididae) and black scale (Saissetia oleae [Olivier]) (Hempitera: Coccidae) (Daane et al. 2005). Olive scale is well managed with biological control due to the introduction and establishment of the parasitoids Aphytis paramaculicornis DeBach and Rosen, and Coccophagoides utilis Doutt (Daane et al. 2005). Black scale is mainly controlled in the Central Valley

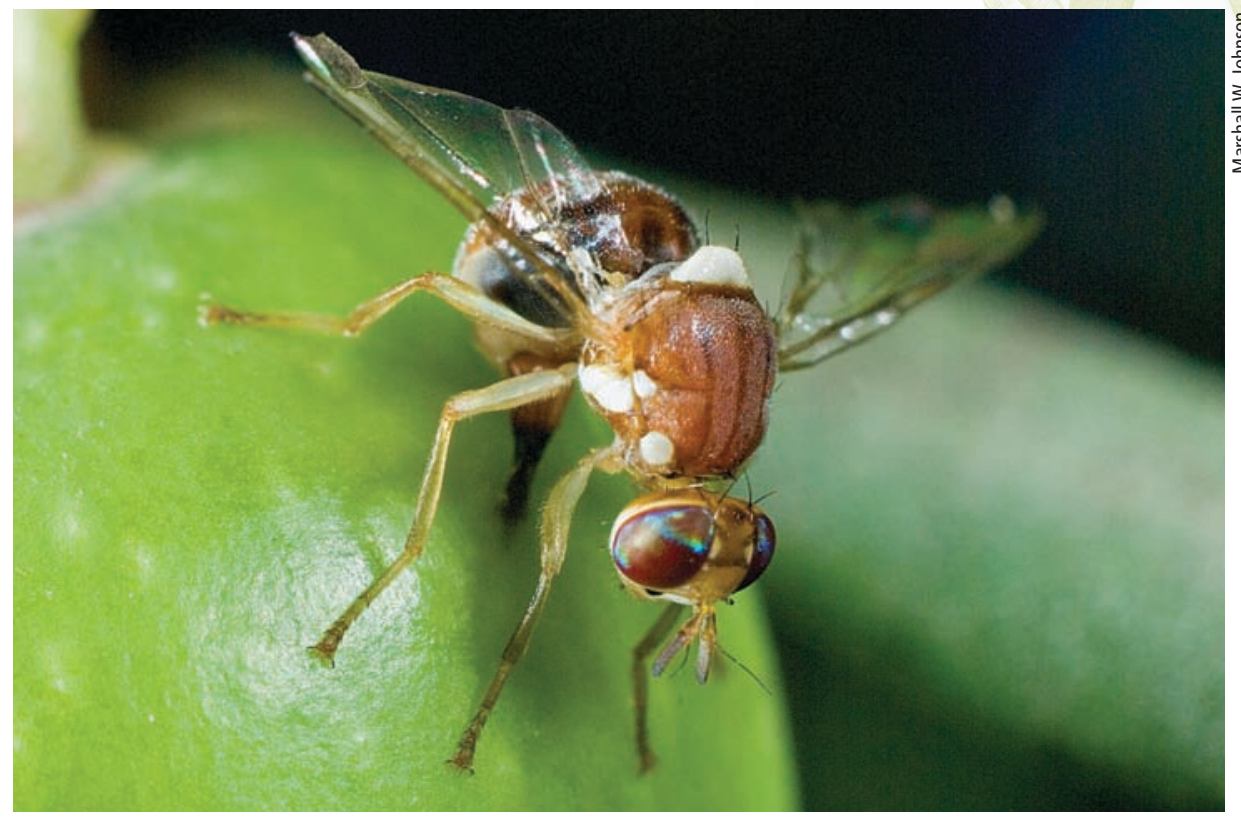

An adult female olive fruit fly deposits an egg into olive fruit.

by pruning infested trees to facilitate greater air movement in the summer, which results in significant desiccation of first-instar crawlers (Daane and Caltagirone 1989).

However, the establishment of olive fruit fly (Bactrocera oleae [Rossi]) (Diptera: Tephritidae) forced many growers onto a weekly treatment regime that runs from mid-June through harvest (September to December), using the spinosad product GF-120 NF Naturalyte Fruit Fly Bait (Dow AgroSciences) (Johnson et al. 2006). This management protocol enables growers to deliver fruit with near-zero infestation levels to the table olive processors. Olives destined for oil pressing may have significant levels of infestation without an appreciable decline in quality, as long as the time between harvest and pressing is minimal (Pereira et al. 2004; Torres-Villa et al. 2003).

\section{Adult behavior and survival}

Olive fruit fly adults may be monitored with flat-panel sticky traps or
McPhail traps (Johnson et al. 2006). The numbers of adults captured in the Central Valley decline during the hottest periods of July and August and increase in September as temperatures decrease (Rice et al. 2003; Yokoyama et al. 2006) (fig. 1). For most insect species, a decline in trap counts suggests a reduction in adult densities in an area. This is not initially the case with olive fruit fly, whose behavior changes as daily temperatures rise.

Avidov (1954) reported that below $62^{\circ} \mathrm{F}$ the adults are inactive. As tem-

\section{As temperatures surpass $84^{\circ} \mathrm{F}$, adult flies become increasingly agitated and egg laying is halted, and above $95^{\circ} \mathrm{F}$ they are motionless.}

peratures increase above the threshold temperature, adult activity increases. Normal activity, flight and egg laying occur between $73^{\circ} \mathrm{F}$ and $84^{\circ} \mathrm{F}$. As temperatures surpass $84^{\circ} \mathrm{F}$, adult flies become increasingly agitated and egg laying is halted, and above $95^{\circ} \mathrm{F}$ they are motionless. Laboratory observations (M.W. Johnson, unpublished) also 
suggest that adults seek and remain near moisture sources as temperatures approach and surpass $95^{\circ} \mathrm{F}$.

Reduced adult fly activity can result in lower trap counts in the field while maximum daily temperatures remain around $95^{\circ} \mathrm{F}$ to $99^{\circ} \mathrm{F}$ and the flies have access to adequate water and carbohydrate sources (Wang et al. 2009a). However, as the frequency at which daily maximum temperatures equal or surpass $100^{\circ} \mathrm{F}$ increases, greater numbers of adults will die due to heat stress, especially when they cannot access adequate quantities of water and food (Wang et al. 2009a, b) (fig. 2). Although adult females may ingest liquid from punctures they make in olive fruit, this secretion does not provide the needed carbohydrates to help them survive heat-induced stress (Johnson and Nadel, unpublished data).
One might assume that acquisition of adequate amounts of food and water would be easy for olive fruit fly adults, which are strong flyers. Using a customdesigned flight mill, Wang et al. (2009b) reported that adults of both sexes held for 7 days at $75^{\circ} \mathrm{F}$ (constant temperature) and provided with ample food (honey and hydrolyzed yeast) and water, were able to fly uninterrupted for an average of 2,164.8 \pm 228.8 yards during a mean period of $1.54 \pm 0.16$ hours (fig. 3 ).

Nonetheless, heat stress and lack of water and food can affect flight ability. Olive fruit fly adults that were subject to the same conditions as described for 7 days and then to water only or no food and water in diurnal temperature regimes $\left(65^{\circ} \mathrm{F}\right.$ at night; $95^{\circ} \mathrm{F}$ or $100^{\circ} \mathrm{F}$ during the day) for 24 hours before the flight test did not perform as well as the control group (fig. 3). All stressed

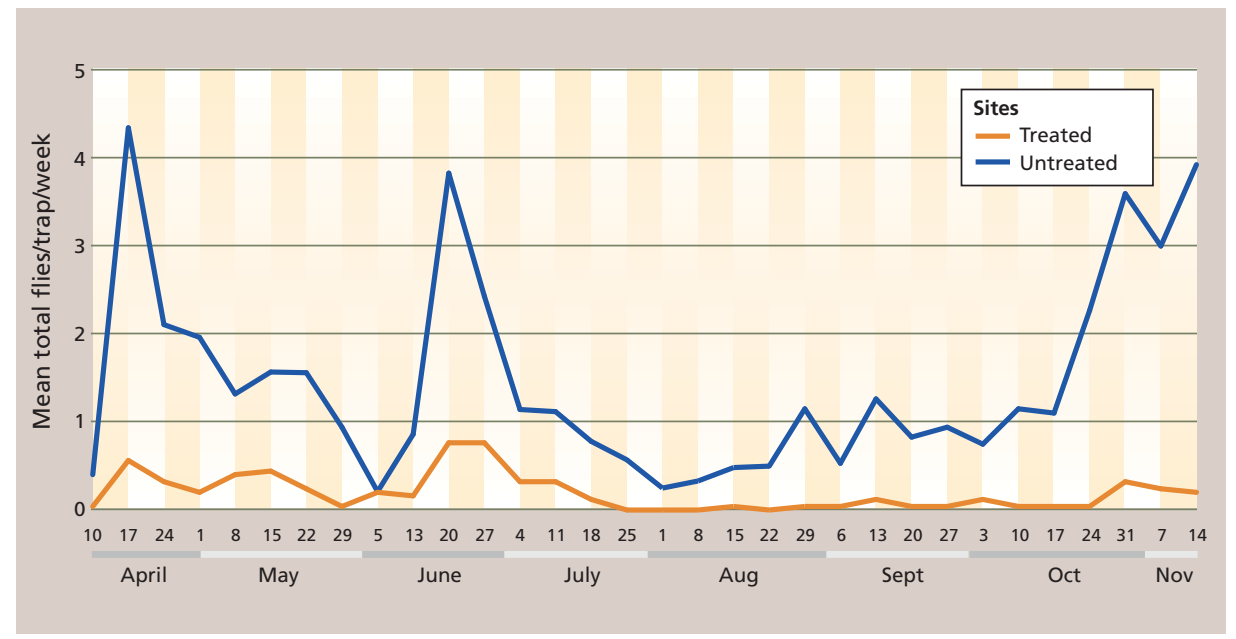

Fig. 1. Average olive fruit fly populations at nine untreated sites (e.g., urban, landscape and abandoned commercial plantings) and five treated (with GF-120) commercial sites in Fresno and Tulare counties during the $\mathbf{2 0 0 3}$ growing season (Johnson, Nadel and Stewart-Leslie, unpublished data).

Fig. 2. Mortality of olive fruit fly adults subjected to 1 to 3 days exposure to $95^{\circ} \mathrm{F}$ and $100^{\circ} \mathrm{F}$, in the absence of food and with and without access to water (Wang et al. 2009b). Different letters above columns representing the same temperature/resource treatment indicate significant differences $(P<0.05$; Tukey's HSD test) within the exposure duration.

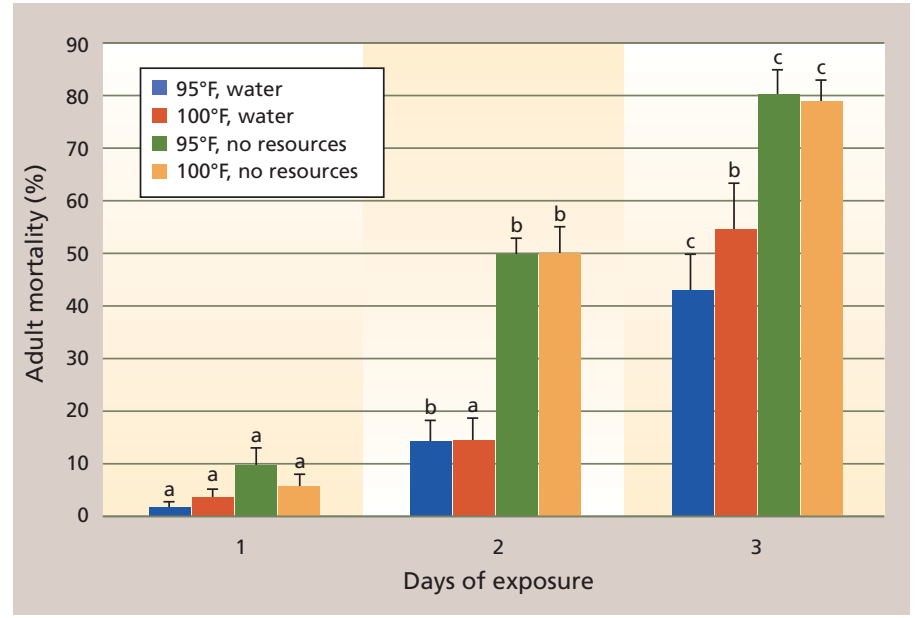

groups of tested flies flew significantly shorter distances $(\geq 42 \%)$ than the control $\left(\mathrm{F}_{6,252}=62.7, P<0.01\right)$. Additionally, individual flies that were denied food and water from the time that they emerged as adults and were held at either $65^{\circ} \mathrm{F}$ at night and $95^{\circ} \mathrm{F}$, or $100^{\circ} \mathrm{F}$, during the day for 1 to 2 days, flew significantly shorter distances ( $\geq 92 \%$ ) than the flies provided no food and water for 24 hours after having access to food and water for 7 days (fig. 3).

In a worst-case scenario, an adult fly that emerges in mid-August in the Central Valley may commonly experience maximum daily temperatures over $100^{\circ} \mathrm{F}$ for 3 consecutive days (LynnPatterson 2006). Without food or water immediately available, an adult will only be able to fly an average of 16.4 \pm 4.4 yards to locate these resources in a dry and unexplored landscape.

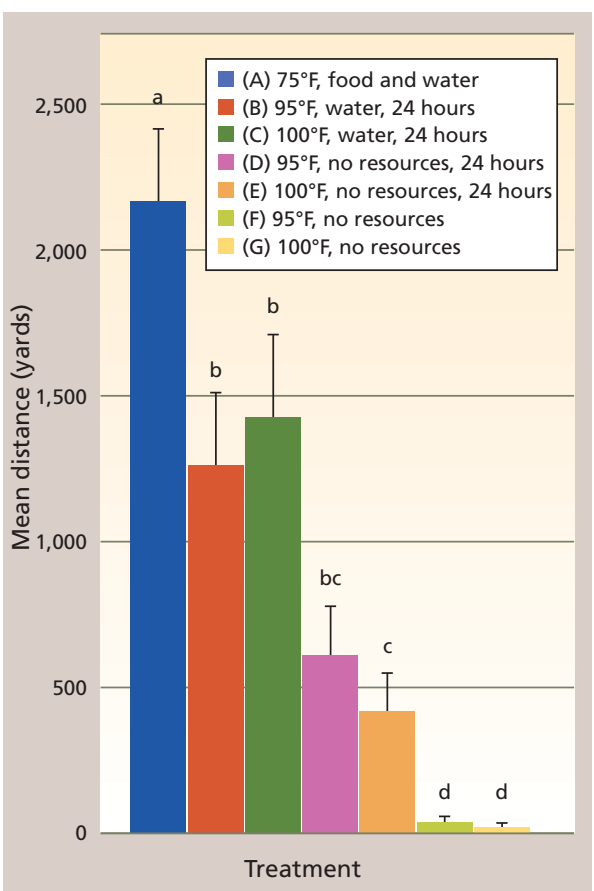

Fig. 3. Mean distances flown by olive fruit fly adults exposed to various temperatures and resources. Flies (A-E) were preconditioned for 7 days at $75^{\circ} \mathrm{F}$ with ample food and water prior to treatment. Treatments were: $(A)$ no treatment (control); (B) preconditioned at $95^{\circ} \mathrm{F}$, then 24 hours of water only; (C) preconditioned at $100^{\circ} \mathrm{F}$, then 24 hours of water only; (D) preconditioned at $95^{\circ} \mathrm{F}$, then 24 hours with no resources; $(E)$ preconditioned at $100^{\circ} \mathrm{F}$, then 24 hours with no resources; (F) no preconditioning, held from 1 to 2 days at $95^{\circ} \mathrm{F}$ with no resources; and (G) no preconditioning, held from 1 to 2 days at $100^{\circ} \mathrm{F}$ with no resources (Wang et al. 2009b). Different letters above columns indicate significant differences $(P<0.05$; Tukey's HSD test). 

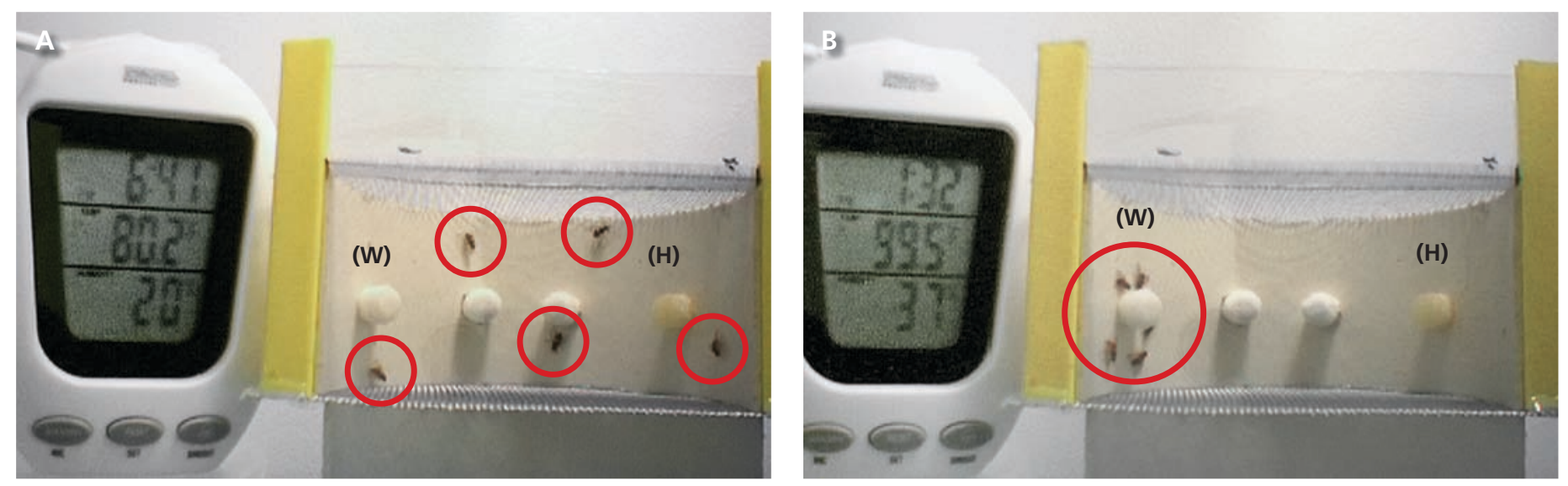

Experimental setup shows (A) the typical distribution of five olive fruit fly adults (circled) within an observation chamber, with cotton wicks and water $(\mathrm{W})$ and honey $(\mathrm{H})$ at a cool temperature $\left(80^{\circ} \mathrm{F}\right)$ and $20 \%$ relative humidity, and $(\mathrm{B})$ the congregation of olive fruit fly adults (circled) around a water wick (W) when the temperature is hot $\left(99.5^{\circ} \mathrm{F}\right)$ and $37 \%$ relative humidity.

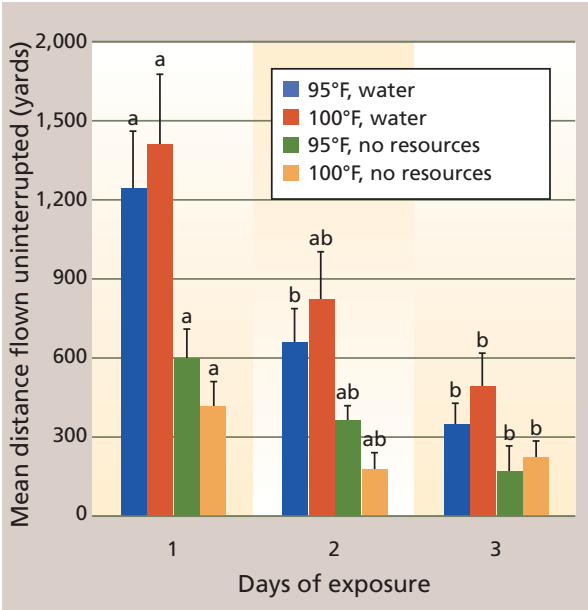

Fig. 4. Mean distances flown by olive fruit fly adults subjected to 1 to 3 days exposure to $95^{\circ} \mathrm{F}$ and $100^{\circ} \mathrm{F}$, in the absence of food and with and without access to water (Wang et al. 2009b). Different letters above columns representing the same temperature/resource treatment indicate significant differences $(P$ $<0.05$; Tukey's HSD test) within the exposure duration.

Such a fly would have an $84 \%$ chance of dying in the first 24 hours, and of those that did survive only about $25 \%$ would be able to fly (Wang et al. 2009b). Additionally, when olive fruit fly adults were held at $65^{\circ} \mathrm{F}$ at night and $95^{\circ} \mathrm{F}$ or $100^{\circ} \mathrm{F}$ during the day over a 3-day period with either water alone or no food or water, those flies that survived one day could fly significantly farther than those that survived 3 days $\left(F_{2,407}=18.7\right.$, $P<0.01$ ) (fig. 4).

\section{Egg and larval survival}

Reproductive dormancy in olive fruit fly subsides as greater numbers of mature fruit appear within the orchard,
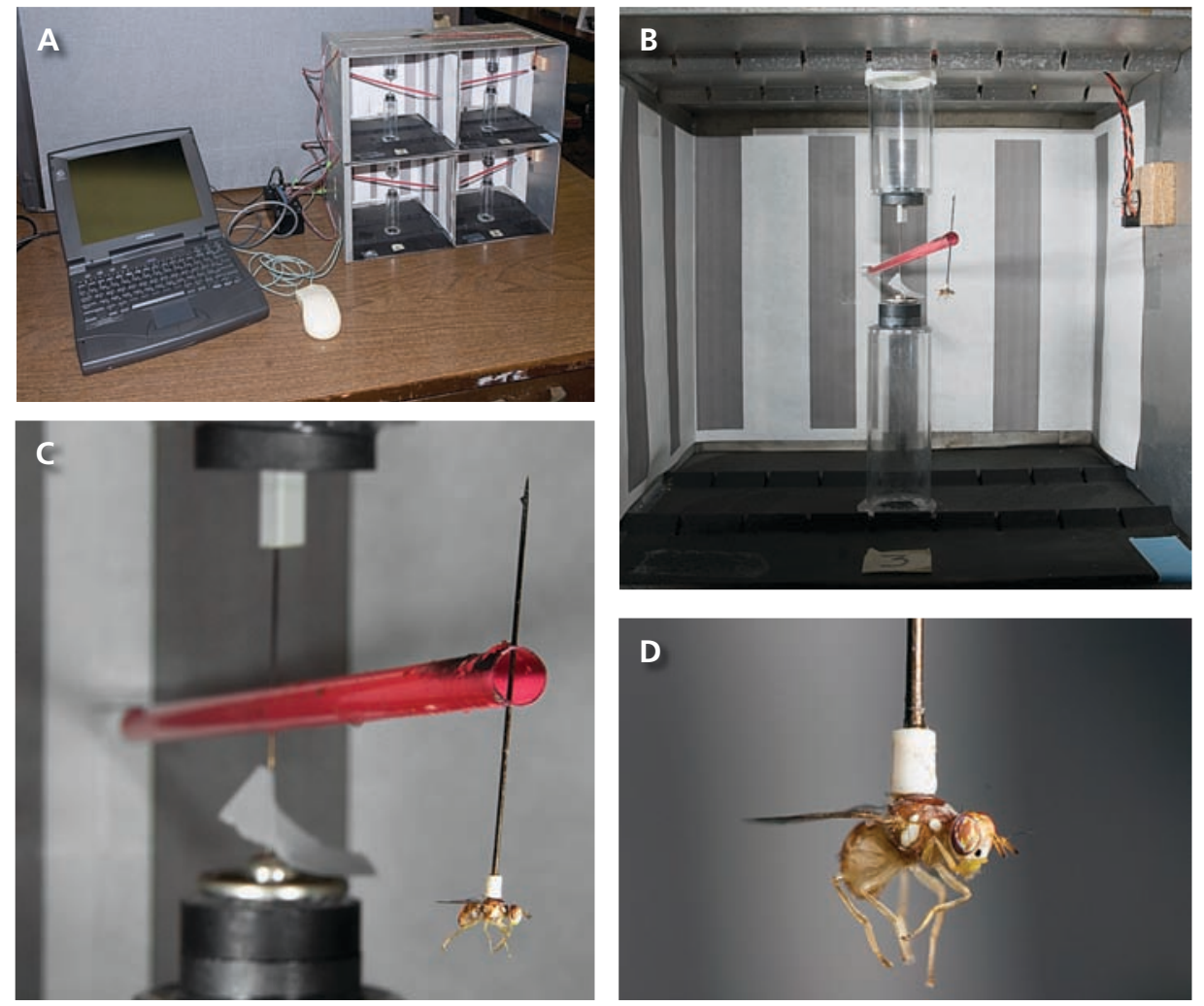

Fly flight is measured using (A) a custom-designed flight mill setup with computer; (B) an individual flight mill unit; (C) a beam that rotates during insect flight; and (D) a tethered fly fastened to a rotating beam.

commonly in late July and early August in California (Burrack and Zalom 2008; Wang et al. 2009a). During periods of high maximum daily temperatures (3 consecutive days at $100^{\circ} \mathrm{F}$ or above in July and August) (Lynn-Patterson 2006), mated adult females may lay their eggs in developing olives prior to morning temperatures reaching $95^{\circ} \mathrm{F}$. No eggs are deposited during the night, even when temperatures are cool enough for normal activity (Avidov 1954; Wang et al. 2009a). Eggs are deposited just beneath the fruit epidermis and may be exposed to high temperatures, depending on where an individual fruit is located on the tree (Wang et al. 2009a).

Laboratory studies showed that adult females held under different diurnal temperature regimes $\left(65^{\circ} \mathrm{F}\right.$ at night and $75^{\circ} \mathrm{F}, 95^{\circ} \mathrm{F}$ or $100^{\circ} \mathrm{F}$ during the day) laid similar numbers of eggs when the temperature was $65^{\circ} \mathrm{F}$ and the experimental chamber was illuminated $\left(\mathrm{F}_{2,55}=0.2\right.$, 
$P=0.852)$. However, under illumination and higher temperatures, females laid significantly fewer eggs at $95^{\circ} \mathrm{F}$ (about four per female) than at $75^{\circ} \mathrm{F}$ (about 12 per female) $\left(F_{1,38}=8.4, P=0.006\right)$, and no eggs were laid at $100^{\circ} \mathrm{F}$ (Wang et al. 2009a).

Even after eggs are deposited within olive fruit, they are still susceptible to the high temperatures common in Central Valley orchards. Eggs within fruit held at $65^{\circ} \mathrm{F}$ (night) and $75^{\circ} \mathrm{F}$ (day) developed into first-instar larvae after 6 days (Wang et al. 2009a). In contrast, eggs within fruit subjected to $65^{\circ} \mathrm{F}$ (night) and $95^{\circ} \mathrm{F}$ (day) had a $49 \%$ mortality rate, and of the first-instar larvae that did develop, none became second instars. When subjected to $65^{\circ} \mathrm{F}$ (night) and $100^{\circ} \mathrm{F}$ (day), no eggs hatched after 10 days exposure and all died. The overall finding was that egg $\left(\mathrm{F}_{3,57}=2472, P\right.$ $<0.001)$ and first-instar $\left(\mathrm{F}_{3,57}=2472, P<\right.$ $0.001)$ mortality increased as exposure time increased (Wang et al. 2009a).

Later field studies showed that maximum daily temperatures in olive trees in the Central Valley (Parlier) varied depending on whether measurements were taken within the canopy interior or the east or west perimeter. Mean temperatures recorded on the west side of the tree canopy in August 2007 were $108^{\circ} \mathrm{F}$ (and over $104^{\circ} \mathrm{F}$ for 26 days) compared to $101^{\circ} \mathrm{F}$ (and over $104^{\circ} \mathrm{F}$ for 13 days) on the east side, and $96^{\circ} \mathrm{F}$ (and never over $104^{\circ} \mathrm{F}$ ) within the canopy interior $\left(F_{2,90}=52.7, P<0.001\right)$. All of these temperatures are high enough to impose some level of mortality on olive fruit fly eggs and larvae. Field studies

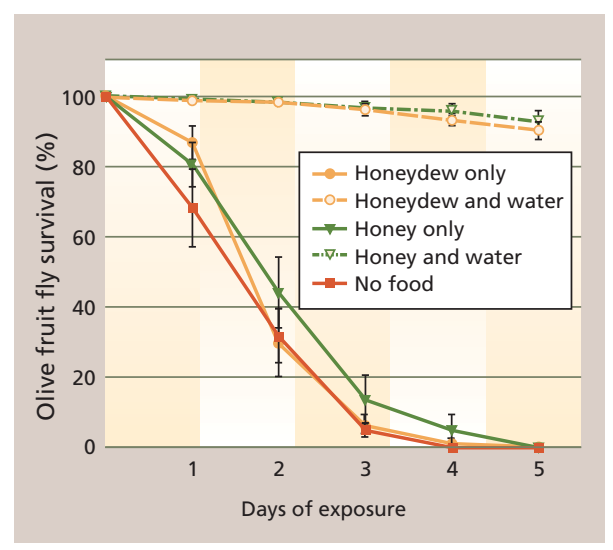

Fig. 5. Survival of olive fruit fly adults when held at $65^{\circ} \mathrm{F}$ (night) and $97.5^{\circ} \mathrm{F}$ (day) with access to various combinations of water, honey and black scale honeydew, or no food or water. in the same locality in mid- and late summer 2007 and 2008 showed that less than $2 \%$ of offspring from eggs laid in olives completed development to the adult stage (Wang et al. 2009a).

\section{Scale honeydew and heat stress}

This information suggests that it is difficult for olive fruit fly adults to survive the high summer temperatures in the Central Valley. Water may commonly be found within or near most orchards from a variety of sources, such as morning dew, creeks, ponds, irrigation water (ditches and canals), sprinklers, drip tape and fan jets. However, fly adults also need carbohydrates to survive heat stress. Honeydew (fresh or dry) produced by black scale is a common carbohydrate source in olive orchards. Our laboratory tests have shown that fly adults provided with honey and water, or black scale honeydew and water, survive temperatures of $65^{\circ} \mathrm{F}$ (night) and $97.5^{\circ} \mathrm{F}$ (day) with minimal mortality compared to adults only provided honey alone, honeydew alone, or no food and water over 5 days $\left(\mathrm{F}_{4,36}\right.$ $=189.9, P<0.0001$ ) (fig. 5) (M.W. Johnson and $H$. Nadel, unpublished data).

The carbohydrate source alone did not reduce the impact of heat on survival. Flies that had food resources (honeydew or pure honey) but no water suffered mortality similar to those flies without food or water. There was a significant interaction between carbohydrate source and days of exposure $\left(F_{20,180}=33.3, P<0.0001\right)$. These results are similar to what we have observed in our laboratory and field studies on olive fruit fly when $50 \%$ honey water was used as a carbohydrate source. These findings are significant because they suggest that olive fruit fly adults could use black scale honeydew to help them survive periods of high temperature in the Central Valley. The management of black scale populations via cultural controls such as the pruning of interior canopies may also contribute to the management of olive fruit fly adults.

\section{Temperature maps and fly activity}

Geographic information systems (GIS) enable the examination of temperature trends over specific areas based on defined criteria, such as temperature levels for specific time intervals. The examination of temperature trends in olive-producing areas in the Central Valley over 10 years (1992-2001) revealed that it was quite common for temperatures to be greater than $100^{\circ} \mathrm{F}$ for 3 consecutive days during mid-July and August (fig. 6) (Lynn-Patterson 2006). On the California coast, these trends were rarely observed. Over this time period, temperatures greater than $100^{\circ} \mathrm{F}$ for 3 consecutive days were more common in the southern (San Joaquin Valley) than the northern (Sacramento Valley) Central Valley (see http://arcims.gis.uckac.edu/CIMIS). By September, most of the Central Valley rarely had 3 consecutive days greater than $100^{\circ} \mathrm{F}$ (fig. 6).; in 2003, olive fruit fly surpassed one adult per trap per week at the end of August and continued to increase into November (fig. 1).

Growers and consultants may wish to use these maps to determine if they can temporarily halt insecticide treatments for olive fruit fly adults during July and August. However, there are many factors other than temperature that influence whether olive fruit fly will be a problem in a particular olive orchard. Olive fruit fly adults with access to adequate sources of water and carbohydrates can survive heat stress in large numbers and will be able to fly long distances (more than 1,000 yards) even when stressed. Growers who consider halting their control programs, especially in the San Joaquin Valley, should take under consideration the irrigation schedules and infestation levels of black scale and other insects that might produce honeydew within their own and neighboring orchards. Also important is the proximity of irrigation canals, creeks, ponds and rivers, as well as abandoned orchards or untreated olives trees used for landscaping, which can serve as an infestation source of olive fruit fly. Morning dew in the orchard may provide a moisture source for flies, and weedy undergrowth in the orchard or neighboring crops can afford some relief from the heat.

Perhaps the most useful information that one can obtain from the GIS maps is knowing when temperatures historically have dropped to low levels that would be conducive to olive fruit fly activity and survival in a particular area. As temperatures decline at the end 


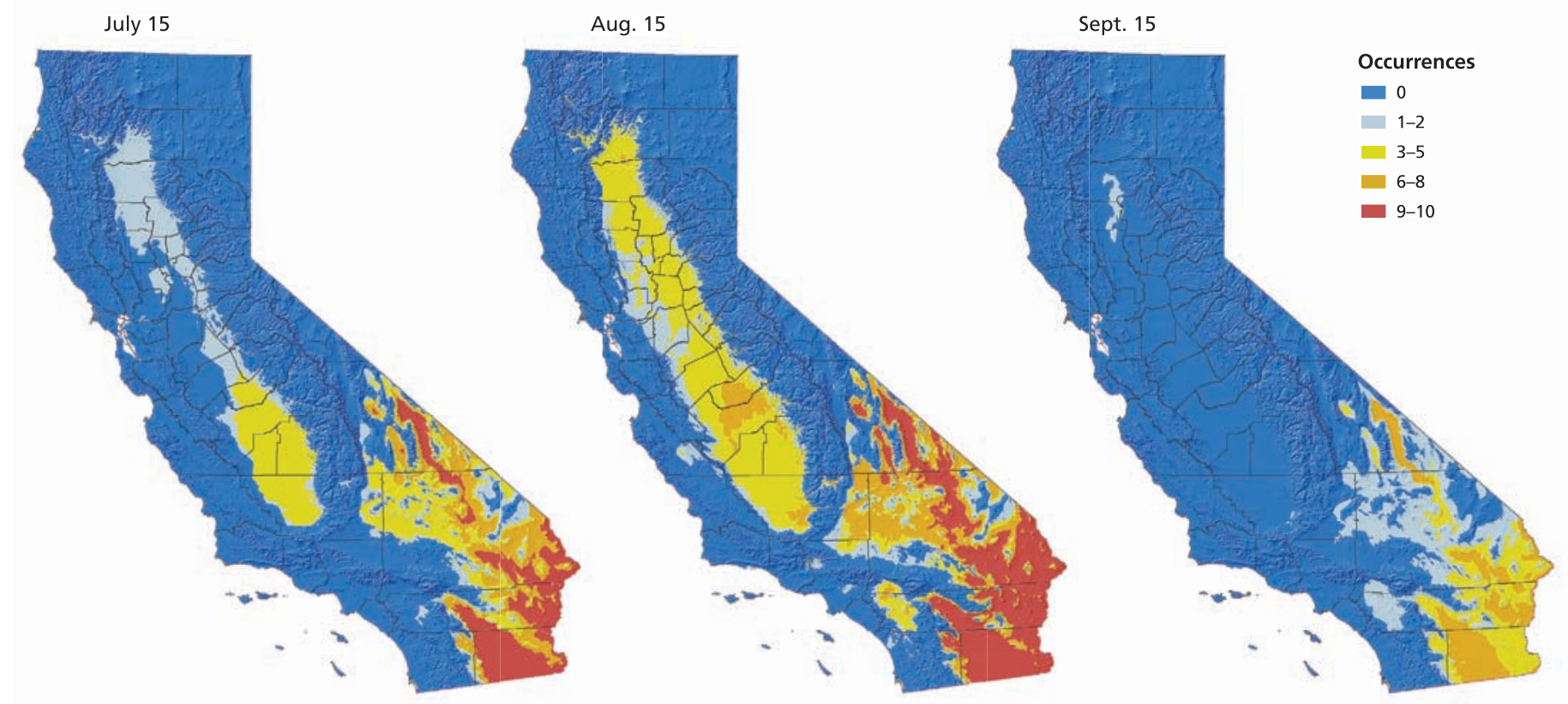

Fig. 6. Mean temperature patterns in California over 10 years (1992-2001), showing number of years (occurrences) with maximum temperatures greater than or equal to $100^{\circ} \mathrm{F}$ for 3 consecutive days ending on July 15, Aug. 15 and Sept. 15 (Lynn-Patterson 2006).

of August, olive fruit are increasing in size and maturing (Martin and Sibbett 2005). Olive fruit fly adults prefer to lay their eggs in the largest olives available (Neuenschwander et al. 1985). As flies return to normal activity in late summer, the olives remaining on the trees are at greater risk of infestation than at anytime during the summer, and protecting the fruit then is of prime consideration.

\section{Future directions}

Research on the ecology and management of olive fruit fly is continuing. A better understanding of the abilities of olive fruit fly adults to disperse among orchards in the summer would be helpful. Given that olive fruit fly adults need carbohydrate sources to survive heat stress, it may be best to continue treating with GF-120 in July and August. The adults are attracted to the sweet fruit fly bait in the GF-120. If stressed flies seek a carbohydrate source in summer, it may be assumed that they would then seek out available bait residues in GF-120. If this is true, the GF-120 may be having a greater impact than realized. This needs to be determined. Also of importance is the impact of summer heat either directly or indirectly on parasitoid natural enemies that are now being released as part of a classical biological control program for olive fruit fly control (see page 21).
M.W. Johnson is Cooperative Extension Specialist and Entomologist, Department of Entomology, UC Riverside; X.-G. Wang is Associate Specialist, Department of Environmental Science, Policy and Management, UC Berkeley; H. Nadel is Supervisory Entomologist, U.S. Department of Agriculture Animal and Plant Health Inspection Service, Plant Protection and Quarantine program, Buzzards Bay, MA; S.B. Opp is Associate Vice President, Academic Programs and Graduate Studies, California State University, East Bay; K. LynnPatterson is GIS Academic Coordinator, UC Kearney Agricultural Center, Parlier; J. Stewart-Leslie is Manager, Consolidated Central Valley Table Grape Pest and Disease Control District, Exeter, CA; and K.M. Daane is Cooperative Extension Specialist, Department of Environmental Science, Policy and Management, UC Berkeley.

\section{References}

Avidov Z. 1954. Further investigations on the ecology of the olive fly (Dacus oleae, Gmel.) in Israel. Ktavim 4:39-50.

Burrack HJ, Zalom FG. 2008. Olive fruit fly, Bactrocera oleae (Gmel.), ovipositional preference and larval performance in several commercially important olive varieties in California. J Econ Entomol 101:750-8.

Daane KM, Caltagirone LE. 1989. Biological control of black scale in olives. Cal Ag 43(1):9-11.

Daane KM, Rice RE, Zalom FG, et al. 2005. Arthropod pests of olive. In: Sibbett GS, Ferguson L. Olive Produc tion Manual (2nd ed.). UC ANR Pub 3353. p 105-14.

Johnson MW, Zalom FG, Van Steenwyk R, et al. 2006 Olive fruit fly management guidelines for 2006. UC Plant Protect Quart 16:1-7
Lynn-Patterson K. 2006. Interactive climate maps for olive fly management decisions. http://arcims.gis. uckac.edu/CIMIS.

Martin GC, Sibbett GS. 2005. Botany of the olive. In: Sibbett GS, Ferguson L. Olive Production Manual (2nd ed.). UC ANR Pub 3353. p 15-7.

Neuenschwander P, Michelakis S, Holloway P, Berchtold W. 1985. Factors affecting the susceptibility of fruits of different olive varieties to attack by Dacus oleae (Gmel.) (Dipt., Tephritidae). J Appl Entomol 100:174-88

Pereira JA, Alves MR, Casal S, Oliveira MBPP. 2004. Effect of olive fruit fly infestation on the quality of olive oil from cultivars Cobrancosa, Madural and Verdea Transmontana. Ital J Food Sci 16:355-65.

Rice R, Phillips P, Stewart-Leslie J, Sibbett S. 2003.

Olive fruit fly populations measured in Central and Southern California. Cal Ag 57(4):122-7.
Torres-Villa LM, Rodriguez-Molina MC, Martinez JA. 2003. Olive fruit fly damage and olive storage effects on paste microflora and virgin olive oil acidity. Grasas Aceites 54:285-94.

Wang X-G, Johnson MW, Daane KM, Nadel H. 2009a. High summer temperatures affect the survival and reproduction of olive fruit fly (Diptera: Tephritidae). Env Entomol 38:1496-504.

Wang X-G, Johnson MW, Daane KM, Opp S. 2009b. Combined effects of heat stress and food supply on flight performance of olive fruit fly (Diptera: Tephritidae). Ann Entomol Soc Am 102:727-34.

Yokoyama VY, Rendon P, Sivinski J. 2006. Psyttalia cf. concolor (Hymenoptera: Braconidae) for biological control of olive fruit fly (Diptera: Tephritidae) in California. Env Entomol 37:764-73. 